\title{
Classroom Interactions in a Cooperative Translation Task
}

\author{
Hui-chuan Wang (Corresponding author) \\ Department of English, Wenzao Ursuline College of Languages \\ PO box 80793, 900 Mintsu 1st Road, Kaohsiung, Taiwan, R. O. C. \\ Tel: +886-7-342-6031-5339Ｅ-mail: cwfranceswang@gmail.com
}

Received: 14-11- 2012

doi:10.7575/aiac.ijalel.v.2n.2p.53
Accepted: 24-12- 2012

Published: 01-03- 2013

URL: http://dx.doi.org/10.7575/aiac.ijalel.v.2n.2p.53

\begin{abstract}
For the past decade, translation learning has become one of the main foci for university language students in Taiwan. However, many studies have shown that translation teachers tend to adopt traditional teaching methods without considering class dynamics and stufdent interactions. This paper therefore looks into the interactions in the researcher's designed cooperative translation task, the Cooperative Translation Task, to see how these interactions helped or hindered students' translation learning. A small class of 25 translation students and two translation teachers were participants. Videotaping and interviews were conducted in order to investigate the interaction modes and student participants' perspectives toward each interaction mode. Six interaction modes were found in this task: within group, between group, translator group and comment-giver group, instructor and students, guest teacher and students, and instructor and guest teacher. Based on the results and participants' responses, suggested teaching guidelines are provided.
\end{abstract}

Keywords: classroom interaction, interaction mode, Cooperative Translation Task, translation teaching

\section{Introduction}

\subsection{Background of the Study}

For the past decade, translation learning has been one of the main foci for university language learners in Taiwan. Since 2003, the Ministry of Education (MOE) has included English Translation I and English Translation II as core courses for students majoring in applied English/foreign languages to develop their translation competence. A close look at the MOE's official syllabi and their teaching guidelines reveals that the MOE suggests a variety of learning activities for translation teachers to utilize in the classroom, including (a) group discussion and presentation, (b) peer correction, (c) error analysis, (d) translation criticism, and (e) comparative analysis. These activities generally share two main features. First, they encourage more interaction and cooperation among students through such activities as group discussion and peer correction. Second, translation problems are not identified by the instructor alone, but also through students' error analysis, translation criticism, and comparative analysis. These main features show MOE's expectation of seeing multiple interactions and students' engagement in translation classrooms.

Apart from the expectations shown in the MOE's official syllabi, it is found that interaction has become one of the key elements in translation work. In the past two decades, translation work has undergone a dramatic change. According to Ulrych (2005), professional translators need client-related skills in sound interpersonal relations with authors, publishers, and requesters. Therefore, interactions like between teacher/student and student/student should be more encouraged in the translation classroom for students' future professions.

As such, more and more translation scholars and teachers have called for alternative methods of translation instruction. Colina (2003) and Kiraly (1995) advocated Communicative Translation Teaching (CTT), which has underlying philosophies resembling those of Communicative Language Teaching (CLT). The main instructional goal of communicative translation teaching is to cultivate students' communicative translation competence and to emphasize the social contexts of texts, which takes customers' needs as priorities and considers the effects on the users of the translation. To build up communicative translation competence, teachers need to integrate multiple tasks such as cooperative learning and peer tutoring, which all encourage interactions.

However, a number of studies have found that many translation teachers still utilize traditional translation teaching methods (Chang, Yu, Li \& Peng, 1993; Liao, 2009; Mu, 1992). In traditional classrooms, students tend to depend heavily on teacher-centered instruction, and teachers accept or encourage the students' passive learning attitudes (Kiraly, 1995). When implementing teacher- and text-centered, and writing-based teaching methods, class dynamics and student interactions are frequently neglected (González Davies, 2004). There are almost no interactions between the teacher and students and among students. As a result, students only follow the teachers' suggestions and rarely reflect up their own translating process, translation styles, and problem-solving approaches.

To date, only a few studies have attempted to apply cooperative learning to translation in Taiwan and there has been limited exploration in the literature about interactions in translation learning activities. With a purpose of developing an interactive and collaborative translation learning context for Taiwanese translation learners, I have been attempting to 
develop a translation learning task, named the Cooperative Translation Tasks (CoTT) in the past two years. The implementations of Prototype I and II of the CoTT have shown the possibility to transform a teacher-centered translation classroom into a student-centered classroom, and more interaction modes have been built up.

The interaction modes in Prototype I have been presented and published in a 2010 international conference on language, literature and teaching (Wang, 2010). This paper is a continuing study working on the interaction modes found in Prototype II of the CoTT and to see how the participants interacted in a cooperative translation task and how those interaction modes shape and influence their learning. Research questions of this study are (1) How did the participants in each mode interact with one another? (2) What can be done to enhance the effectiveness of interactions for translation learning?

\subsection{Design of the Cooperative Translation Tasks (CoTT)}

The usage of the term task of the Cooperative Translation Tasks (CoTT) here follows González Davies' (2004) definition. Her definitions distinguish the relationships among the three instructional actions: activities, tasks, and steps. González Davies (2004) defined a task as follows:

Task will be understood as a chain of activities with the same global aim and a final product. The full completion of a task usually takes up several sessions. In each of these, the activities lead along the same path towards the same end. (p. 23)

Based on her definition, the Prototype II of the Cooperative Translation Task (CoTT) includes five sessions (see Table 1), which can be divided into three stages: Pre-presentation Stage, Presentation Stage, and Post-presentation Stage. These sessions were constructed based on the following rationales.

1. The teaching guidelines in the official syllabi for English Translation I and English Translation II (2005), issued by the Ministry of Education (MOE),

2. Five major features of cooperative learning,

3. Related literature on peer response and teacher response,

4. Process-oriented and product-oriented translation evaluation, and

5. The researcher's previous implementation of the Prototype I of the CoTT.

Table 1. Five Sessions of Prototype II

\begin{tabular}{ll}
\hline Sessions & Prototype II \\
\hline Session 1 & Written Peer Response \\
\hline Session 2 & Student Seminar \& Teacher Seminar \\
\hline Session 3 & Oral Peer Response \\
\hline Session 4 & Oral Teacher Response \\
\hline Session 5 & Final Revisions \\
\hline
\end{tabular}

Below are the brief descriptions of each session of Prototype II of the CoTT for the current study.

\subsection{Prototype II of the CoTT (Cooperative Translation Tasks)}

Pre-presentation Stage: Session 1

In Session 1, Written Peer Response, two randomly selected groups exchange translations for written peer editing. Each group gives comments and suggested translations on a peer response sheet and returns it to the translator group by email. The translator group decides whether to accept the suggestions and makes appropriate revisions for the class presentation.

Presentation Stage: Session 2, 3, 4

In Session 2, Student Seminar \& Teacher Seminar, to keep students more engaged in discussions and avoid withingroup chatting, there is a between-group discussion, named Student Seminar. To encourage the students to consult the teachers, Teacher Seminar is arranged to give students a chance to engage in face-to-face discussion and cooperation with the teachers. These two seminars are conducted simultaneously. Each group (five members) sends one member to Teacher Seminar, and the other four members go to four different student seminar tables. All the seminar participants' job is to review a translator group's presented products. A seminar sheet is given as an organizational construct for the students to take notes and list their suggestions.

In Session 3, Oral Peer Response, after peer review activities, each translator group orally presents comments and discussion results collected in Teacher and Student Seminars. The instructor plays a role of a moderator to create various interactions in this session. The instructor leads the translator groups to share comments and invite more questions from the class.

In Session 4, Oral Teacher Response, to provide the students with the teachers' perspectives on their translations, one or two teachers give their oral comments. If there is a guest teacher, his or her comments are given first. The acceptable 
and unacceptable translations are pointed out and the teachers provide the suggestions for final revisions.

Post-presentation Stage: Session 5

In Session 5, Final Revisions, after the translation reviews in class, students are asked to use both process-oriented and product-oriented methods to present their final revision process and product. Each translator group is required to use a new mediating artifact, the Comment function in word-processing software, to insert (1) comments from teachers and peers, (2) acceptance level of comments, and (3) the final translation.

\section{Method}

\subsection{Participants}

The participants were 25 technological university students who majored in Applied English and two translation teachers. There were 3 males and 22 females taking this course, named English Translation. They were divided into five groups. They were all seniors, but they did not have any translation learning experience before. The class met two hours each week, and the Prototype II took three weeks, six hours in total. The genre for the translation assignment was story, which was decided by the instructor. However, each group could select a story they liked and translate it from English to Chinese. The average translation words were around 450-500. A consent form written in both Chinese and English was given to the student participants to ensure that all the student participants knew that they were taking part in a research study. The teacher participants, two female teachers who played the roles of the instructor and the guest teacher respectively, took part in this study.

\subsection{Video Recording}

Because the classroom was not equipped with video cameras, a video camera was mounted in the back of the classroom by the researcher. However, when group work began, the camera could not capture group interactions. Hence, the researcher took the camera in her hands and moved to each seminar table to film the within-group and teacher-student interaction. Each session in Prototype II was videotaped. The permission to record the class on video had been obtained from the students before the camera was set up.

\subsection{In-depth Interviews}

Two kinds of interviews were conducted. First, weekly interviews were conducted with a group of students in order to monitor the students' changes in perspectives and observations of the interactions. Prototype II consumed three weeks of class time, so three interviews with the same group were conducted. The weekly interviews were conducted immediately after class. Since each member of a group went to different seminar tables, interviewing a single group could provide the researcher sufficient data to understand what happened in each student seminar. Therefore, the present study employed Patton and Patton's (2001) purposeful random sampling to select one group from the five groups by drawing lots, and this group showed their willingness to participate in the weekly interviews. These five students were given numeric labels from II-1 to II-5, with Roman numeral II representing Prototype II and the Arabic number referring to the order in which the interviewee spoke. In other words, II-5 was the last student who spoke in the interview. Each interview lasted for around 40 minutes and was recorded.

\subsection{Data Analysis}

In this study, all the interviews were transcribed and the transcriptions were translated into English for data analysis. Interview transcripts and notes were analyzed by using the constant comparative method, which was derived from the "Ground Theory" proposed by Glaser and Strauss (1967). The constant comparative method is a process in which data were coded, categorized, and theorized. The videos were viewed twice in order to find possible interaction modes and how the participants interacted with one another.

\section{Results and Discussion}

\subsection{Within-group Interaction}

It is clear that friendship plays an important role for the students to help group members. Friendship can be seen as a social attraction for grouping. The benefits of this grouping are that students with similar linguistic and cultural backgrounds will show a strong preference to be in the same group for peer support because social attraction usually comes from perceived similar backgrounds, proximity, and emotional ambience (Liu \& Hansen, 2005). These similar backgrounds, attitudes, or viewpoints will be likely to promote affiliative feelings (Deutsch, 1962). Students in the current study showed a strong preference for forming groups based on friendship or a pre-existing cooperative relationship. They also complained the difficulty in working with the members of other groups in Student Seminar, as they had not cooperated before. They did not how to stimulate the other members to contribute their opinions.

As Dörnyei (1997) suggested, the affective domain plays an essential role in the success of cooperative learning. He attributed this positive interaction to the interrelated roles in group dynamics. His suggestions for enhancing group cohesiveness are similar to those of Johnson et al. (2002) for increasing positive interdependence. He emphasized the need of team building for team members to know each other and develop the trust and skills to work together. This is especially true when a group is formed by the teacher or at random, and not by the students. Thus, if the CoTT is conducted under time constraints, it is suggested that the teacher allows students to form groups based on friendship, acquaintance, or their previous cooperative experience so that the learners may generate more comments in a short discussion time. 


\subsection{Between-group Interaction}

In Prototype II, the between-group interaction took place in Student Seminar. The members came from separate groups, and they were all assigned one language level (vocabulary, sentence, discourse and extralinguistic levels) for review. The discussions were not as smooth as expected, as the students were not acquainted with each other. Moreover, having no leader to initiate discussion, sometimes they did not know how to start. With a lack of acquaintance and group cohesiveness among members, there were no established group dynamics to increase the members' engagement. The students did not dare to accuse the others of avoiding responsibility, for they did not want to damage their friendships. If the members were acquainted each other, it would be easier for members to negotiate the job assignments and responsibilities.

It can be inferred that for a success in between-group discussion, complicated activities should be avoided, as students usually become confused about their roles in the task. Complicated tasks generally require division of labor among group members, so if the cooperative relationship has not been formed previously, it will be hard for group members to help each other. This situation may worsen when there is no leader and the members have similar roles in the discussion. Some students may try to avoid responsibility, as the other members can finish the task just as well without their contributions. Even though they might care for their friendships, those students may still act very passively, acting more like listeners. For situations like this, it appears that the principles of the Discussion Group, one of the cooperative learning activities, can provide some help in solving this problem.

In a Discussion Group, it is important to give students a well-defined aim, and a leader should be assigned by the teacher or chosen by the members. This leader's main responsibility is to ensure member participation and engagement. Here, in the CoTT, it is suggested that this group leader confirm that all members understand their roles, the task they should complete, and the flow of the discussion.

Slavin (1997) suggested three ways to ensure student participation: asking members to write down opinions, assigning certain parts of a topic, and giving sufficient time. If incorporating Slavin's suggestions, a translation teacher can ask each group to take notes of what has been discussed, ask the leader to assign responsibilities, and give more discussion time or ask a group member to play the role as time controller. Moreover, to ensure that all group members are participating, one main feature in cooperative learning can be employed: individual accountability. Students should take individual notes, and the notes should be turned in by the group, so that individual accountability contributes to the grade on group performance. The leader should be responsible for asking the members to finish their own jobs in order to ensure that every member contributes a fair share.

\subsection{Translator Group and Comment-Giver Group Interaction}

As for the interactions between the translator group and comment-giver group, generally the comment-giver group gave comments politely for fear that the translator group might lose face, and they attempted to protect their friendship. However, their comments became more critical when giving oral comments. It is interesting to note that one reason for being critical was that students wanted to exact revenge for being criticized by another group. Because their face had not been saved, they felt that they did not need to concern about the others' faces. Thus, their remarks were more critical, with a slightly impolite tone.

Critiquing is a face-threatening act, and we can see that most of the students tried hard to save face for their classmates in order to protect their friendship. However, when they felt they were 'under attack,' and they wanted to 'fight back.' This finding was consistent with the results of my studies in translator seminars (Wang, 2009). Students' arguments gained in strength, from mild to strong, when they heard more arguments against them, and they started getting used to debating. Even though some students were slightly impolite during discussions, it seemed that students had learned the skills to argue and support their assertions.

As most Taiwanese students have little experience in discussion and debating, teachers should provide as much experience as possible, even though some strong arguments may develop when students become more critical. Teachers should stir their students and help them discover their potential for critical thinking by experiencing different developmental stages. However, rude or impolite behavior has to be dealt with by the instructor. Some social and communication skills should be taught during the training of peer responses so that some conflicts can be avoided.

Second, the translator groups did not actively respond to the comment-giver groups, as they believed the speaking time belonged to the comment givers. To interrupt or argue with them might offend them. Thus, they did not talk until the instructor encouraged them to talk or gave them permission to speak. In other words, students were trying to protect their friendships and to be polite to both the comment-giver group and the teacher. To improve this situation, the teacher should act as a mediator to remind the translator group that they can argue in favor of their opinions and encourage debate.

\subsection{Instructor and Student Interaction}

It is found that the students tended to rely on the instructor's instructions to complete the tasks. The instructor's talk seemed authoritative to learners. Whenever the instructor joined the discussion or interrupted the presentation, the audience's attention was drawn. When the instructor asked the comment-giver group questions or required the translator group to respond to the comments, or asked the audience to vote for alternative translations, most of the students were attentive to what was happening on the stage. The authority conferred on the teachers in the students' minds is obvious, and the students got used to being extrinsically motivated by the instructor. 
However, students pointed out several advantages of joining Teacher Seminar. First, teachers could help them solve the problems that Student Seminar could not solve. Moreover, they learned that the teachers had different opinions on the same translation, and they were interested to know how the teachers looked at the translation from different perspectives. They used to think that teachers had so-called 'correct translations.' The learners pointed out that the biggest problem in peer discussion was that it was easy for them to abandon their own opinions, especially when their classmates insisted on their opinions. The teachers' discussion taught them that they could hold different opinions or argue with peers. The third advantage was that the teachers increased their confidence, and they became aware of their own abilities in translation. Student Participant II-2 mentioned her excitement during Teacher Seminar:

The discussion with the teachers was exciting. At the beginning, we dared not to express ourselves because the teachers did not point out any problems. It could have meant that the teachers thought the translation was acceptable. But when we pointed it out, it seemed that the teacher simply did not notice it, not that it was a good translation.

To alter the traditional perception of a teacher's role, students' new awareness of the teacher's role may need to be raised. It can be done right after the discussion in Teacher Seminar. The instructor can ask the seminar participants what they have observed about the teachers' roles and students' roles in the seminars, and what they have learned from this activity. The students will be able to see the value of Teacher Seminar and their contributions to their own learning.

If students are used to teacher-centered learning, the teacher should shift the approach gradually. A sudden change may make students feel insecure, and they may even believe that the teachers are lazy. The scaffolding should be drawn little by little until students are accustomed to a student-centered discussion.

\subsection{Guest Teacher to Student Interaction}

The guest teacher expected more active participation from the students who took part in Teacher Seminar. She gave the power to the students and let them initiate discussion. If she found the students did not actively ask questions or raise questions for discussion, she invited one or two students to start and listened to their opinions first. However, not many of the students had the courage to speak to the guest teacher face to face. They were afraid that they would bring up 'stupid' questions and did not know how to start a discussion with a teacher. In other words, personal contact with a teacher and a lack of self-confidence caused the stress.

Therefore, the first priority for positive interaction between the guest teacher and students is to help students believe in the role the guest teacher plays. The teacher can play a more supporting role and act more like a group member. Instead of expressing professional suggestions, the guest teacher should first invite more opinions and listen to students first, and then guide students to think from multiple perspectives. The teachers' suggestions can be drawn inductively by the students.

\subsection{Instructor to Guest Teacher Interaction}

The interactions between the instructor and the guest teacher demonstrated the advantages of team teaching in a translation classroom. First, the two teachers' different comments on the same translation raised the students' awareness of alternative translations. The students discarded the belief that there was a 'correct translation.' Second, the negotiation process between the two teachers helped students understand that a better translation was achieved through negotiation, especially when the guest teacher raised translation problems and the instructor continued the issues. The students observed the discussion process and later might imitate the process in their own discussion. Finally, a translation draft can be discussed in terms of the two teachers' professions, so validity and reliability of teacher reviews can be achieved.

The clear benefits of team teaching in reviewing translations are found in the present study. However, in reality, teachers may find it difficult to invite a guest teacher for regular translation exercises. It is herein suggested that the team teaching be conducted for the midterm or final evaluations only. The target teacher can be another translation teacher in the same department, or ideally one from another school, as in the present study. These two teachers can work together on the translation evaluation of two classes.

\section{Conclusions}

Interactions used to be a neglected part in traditional translation class. The six interaction modes found in Prototype II of the CoTT has proved how interactions among students and teachers benefited students in a deep learning of translation, development of critical thinking, and cooperation between/among translators. However, each mode had different problems due to students' learning nature. The current study provided the teaching implications for translation teachers to solve those problems. For a more active and productive within-group discussion, group formation can be based on friendship, acquaintance, or previous working experiences. To ensure student participation, a leader and individual responsibility should be assigned according to a well-defined aim. When students are used to peer response tasks, it is critical to teach students social and communication skills to avoid a negative climate from impolite behavior. Finally, turning a teacher-centered translation classroom into a student-centered one can start with a shift from a traditional teacher's role into a moderator by removing scaffolding instruction gradually. This study is limited to the size of the class. The interaction modes may be different from the bigger class. The implementation of the CoTT in a big class can be the next step for the teachers who teach a big translation class. 


\section{References}

Chang, P., Yu. Y., Li, Z., \& Peng, M. (1993). 英漢翻譯教程 (English to Chinese Translation Courses). Taipei: Bookman. Colina, S. (2003). Translation teaching, from research to the classroom: A handbook for teachers. Boston: McGraw-Hill. Deutsch, M. (1962). Cooperation and trust: Some theoretical notes. In M. R. Jones (Ed.), Nebraska symposium on motivation (p. 275-319). Lincoln, NE: University of Nebraska Press.

Dörnyei, Z. (1997). Psychological processes in cooperative language learning: group dynamics and motivation. Modern Language Journal, 81 (4), 482-493.

Glaser, B., \& Strauss, A. (1967). The discovery of grounded theory: Strategies for qualitative research. Chicago: Aldine Publishing Co.

González Davies, M. (2004). Multiple voices in the translation classroom: activities, tasks, and projects. Benjamins translation library. Amsterdam: J. Benjamins Pub.

Johnson, D. W., Johnson, R. T., \& Holubec E. J. (2002). Cooperative Learning in the Classroom. Alexandria, VA: Association for Supervision and Curriculum Development.

Kiraly, D. C. (1995). Pathways to translation: Pedagogy and process. Kent, OH: The Kent State University Press.

Liao, B. S. (2009). The Implications and Implementation of Communicative Translation Teaching. Compilation and Translation Review, 2, 65-91.

Liu, J. \& Hansen, J. (2005). Peer response in second language writing classrooms. Ann Arbor: University of Michigan Press.

Mu, L. (1992). 中國翻譯教學研究 (Translation Teaching in China). Taipei: Shanghai Foreign Language Education Press.

Patton, M. Q., \& Patton, M. Q. (2001). Qualitative evaluation and research methods. Newbury Park, Calif: Sage Publications.

Slavin, R. E. (1997). Cooperative learning: Theory, research, and practice. Massachusetts: Allyn and Bacon.

Ulrych, M. (2005). Training translators: Programs, curricula, practices. In Tennent, M. (2005). Training for the new millennium: pedagogies for translation and interpreting. Amsterdam: J. Benjamins.

Wang, H. C. (2009). Experiential learning and negotiation in translation classrooms: Simulated seminar. 2009 International Conference on Translation and Interpretation, 221-236, 日昇.

Wang, H. C. (2010). Interaction modes in a cooperative translation task. 2010 International Conference on Language, Literature, and Teaching, 131-144, 全華. 